
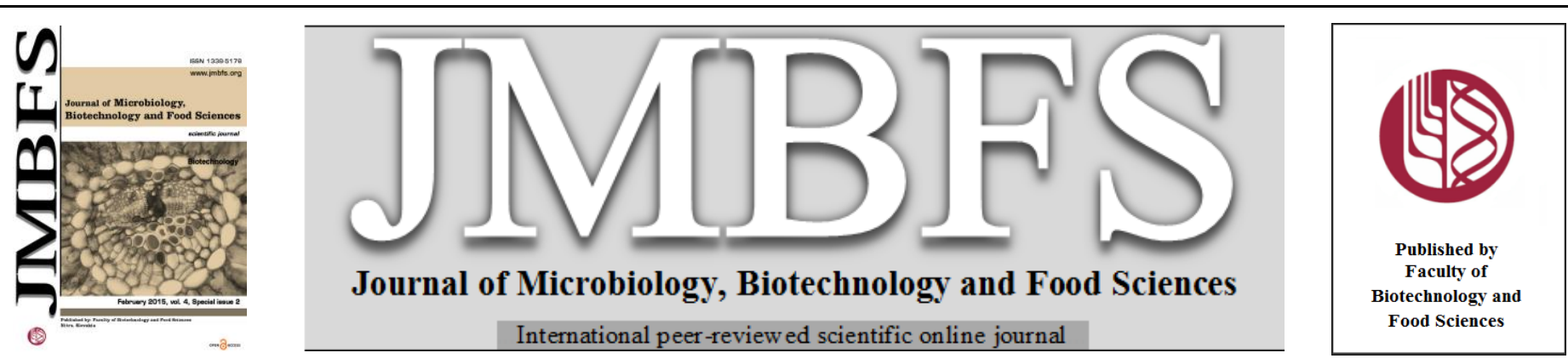

\title{
THE USE OF HIGH-PERFORMANCE LIQUID CHROMATOGRAPHY AS SCREENING TECHNIQUE FOR PECTIN AND PECTIN SUBSTANCES OF DIETARY FIBERS
}

\author{
G.N. Ignatyeva $^{12^{*}}$, Patricia Melgarejo Juan ${ }^{3 * *}$, Sandra Monera Picazo ${ }^{3}$, Desirée Follana Álvarez ${ }^{3}$ \\ Address(es): \\ 1 "Citromil", ${ }^{2}$ "Mitrasolution", Murcia, Spain, c. Alfonso X El sabio, 4, Abanilla, 30640, Murcia, Spain \\ Tel: (34) 620207698 e-mail: *GJP.Ignatieva@ Gmail.com. \\ ${ }^{3}$ University Miguel Hernández, ctra.3,2km Beniel 03312, Alicante, Spain e-mail: ** patricia.melgarejo.juan@gmail.com.
}

*Corresponding author: GJP.Ignatieva@Gmail.com

doi: 10.15414/jmbfs.2015.4.special2.30-41

\section{ARTICLE INFO}

Received 1. 12. 2014

Revised 10. 12. 2014

Accepted 13. 1.2015

Published 2. 2. 2015

Regular article OPEN $\partial_{\text {ACCESS }}$

\begin{abstract}
The peak of the unspecified compound of quantitative analysis of organic acids in biological materials by using high-performance liquid chromatography was identified. This peak corresponded to polygalacturonic acid. A High-performance liquid chromatographic method was developed to identify and quantify of water soluble pectin fraction and insoluble pectin fraction, galacturonic acid and polygalacturonic acid. The method based on the extraction of free water soluble fraction with phosphate buffer $(\mathrm{pH} 4.8)$ or with $0.01 \mathrm{~N}$ phosphoric acid and on the acid hydrolysis of insoluble pectin fraction in presence $0.1 \mathrm{~N} \mathrm{HNO}_{3}$. The pectin fractions were separated and determined on a $\mathrm{C} 610 \mathrm{H}$ column using elution with $0.01 \mathrm{~N}$ phosphoric acids and ultraviolet detection at $210 \mathrm{~nm}$. Galacturonic acid and polygalacturonic acid were used as internal standard. The calibration curves were presented for each of the standards. The determinations were performed in the linear range of $0.04 \div 0.17 \% \mathrm{w} / \mathrm{v}$ for both pectin fractions. Proposed procedure can considered as a rapid method for quantitative pectin determination in the food, food nutrition's food, and pharmaceutical agents.
\end{abstract}

Keywords: High-performance liquid chromatography method, water soluble pectin fraction, insoluble pectin fraction, polygalacturonic acid, dietary fiber, food, nutrition's food, pharmaceutical agents.

\section{INTRODUCTION}

Pectin and polygalacturonic acid have applications as therapeutic and diagnostic pharmaceutical agents such as the magnetic resonance imaging agent Lumen Hance (Gregory, W et al., 1999). It has been demonstrated that modified pectin (MPC) to be effective in suppressing or preventing metastases (Eliaz, I., 2001; Eliaz, I., 2011).

Oligogalacturonic acids (OGAs) released from the homogalacturonan backbone have been shown to exhibit a number of biological activities in plants such as induction of defense response and regulation of growth and development (Ridley, B. L. et al.,2001; Kerry hoster Caffall et al.,2009). Apart from their hormone-like function in plants, OGAs have recently attracted intense interest since they have been demonstrated to inhibit the adherence of bacteria to epithelial cells and might therefore be used as therapeutic agents (Guggenbichler, J. P. et al, 1997(a); Guggenbichler, J. P. et al., 1997(b)). Therefore, reliable analytical methods for the unambiguous characterization of pectin degradation products are urgently needed.

Determination of individual pectin contents in fresh or dried biological materials and in their fiber products is an important mixed biopolymer analysis means and food nutrition analysis means for evaluating structure, quality and variety. As a result of the type preparation commercial fibers the pectin in dietary fibers is rich in GalA and contains only small amounts of neutral sugars. In the past years the analysis of water soluble pectin fraction and insoluble pectin fraction in dietary fibers has attracted the interest of the researchers due to their beneficial effects on health. It has been established that fibers in the diet can exert an antioxidant effect; preventing development of atherosclerosis. Various methods have been reported for the determination of pectin in foods, or biological materials including titration (Alfonso, Garcia, E., 2010), spectrophotometry (M. A. Monsoor et al., 2001), mass spectrometry (Piet J.H. et al., 1998; Thomas Stoll et al., 2003). Most of these methods are time-consuming. There is a need for a rapid analytical screening procedure to analyze the pectin. Many review articles covering different theoretical and practical aspects of chromatographic methods and its applications in different fields appeared: an HPLC (Geovana Rocha Placido Moore et al., 2005), high resolution size-exclusion chromatography (HRSEC) (S. Vidal et al., 2001), high-performance size-exclusion chromatography (HPSEC) (Sang-Ho Yoo, et al., 2006; Beda Marcel Yapo et al., 2007). Schols and other were able to separate pectin populations present in commercial pectin compounds according to their charges, using an HPLC system equipped with an anion exchange column (MA7P column) on an analytical scale (Schols et al., 1989) (Piet J.H. et al., 1998). The HPLC method with aWAX column was found to

discriminate between commercial pectins efficiently: pectins with similar DM (degree of methyl-esterification) or similar DS (degreeof substitution: methyl-est ers and amide groups) having different physical properties showed various populations (S. E. Guillotin et al., 2007).

The aim of our research work was the optimisation and validation of a rapid, simple, accurate, selective, sensitive and inexpensive method for simultaneous determination of the pectin and pectin degradation products. In the other part of this work we report the analysis of water soluble pectin fraction and insoluble pectin fraction in dietary fiber samples by HPLC coupled with UV detectors in order to characterise their structure.

\section{MATERIAL AND METHODS}

Chemicals. Galacturonic acid, polygalacturonic acid, organic acids (or their sodium salts) were purchased from Fluka (Buchs, Switzerland) and Aldrich (Steinheim, Germany), from Sigma (St. Louis, MO, USA).

Sampling. Forty five samples were assayed, which included the dietary fibers from "peel", "frit", and "core" of dry y fresh lemons and from fresh oranges. To simplify discussion of the result pectin extractions each of the 45 samples was identified with an abbreviation such as the water soluble pectin fraction (WSP) and insoluble pectin fraction (AIP). The dietary fibers were home-made and obtained after by expression of orange (Citrus sinensis, Valencia late) and lemon (Fino), obtained from the Spain market.

Approximately $1 \mathrm{~kg}$ of the dried and frozen fresh lemon, orange peel, "frit", "core" were used to obtain samples of fibers. The source for these compounds (peel, frit, and core) is sub-products in citrus juice processing. After the juice extraction process, the samples were collected and dried in an air-oven at $40^{\circ} \mathrm{C}$ for $48 \mathrm{~h}$. The moisture content of the dried samples was $10 \%$. Dried samples were then finely ground to $1.0 \mathrm{~mm}$ in size and kept in a desiccator until used. The other part of citrus peel, frit and core was collected and frozen at $-20^{\circ} \mathrm{C}$ for one year. The moisture content of the frozen fresh peel, frit, and core samples were $80 \%$. Chemical, mechanical, thermal processing was used for fiber production. 
Fibers were isolated as soluble and insoluble non-starch polysaccharides. To investigate the influence of different structural features of fibers on its physicochemical properties the treated fibers with 2-propanol were also air-dried at room temperature. After air-drying, dry fiber samples with different structural features were crushed to a powder and made a particle classification using a system to separate fractions of particulate size $0.100 \mathrm{~mm}$ and $0.250 \mathrm{~mm}$.

The insoluble pectin fraction (AIP) was submitted followed by acid hydrolysis (Ravin, Gnanasambandam, Proctor, A, 1999). Ground fibers were extracted with $0.1 \mathrm{~N} \mathrm{HNO}_{3},\left(1: 20\right.$, ratio), at $90^{\circ} \mathrm{C}$ for $40 \mathrm{~min}$ in a rotary evaporator, cooled to room temperature in a water bath, and centrifuged $(15 \mathrm{~min})$. The supernatant was collected, and the sediment was extracted twice more in $0.1 \mathrm{~N} \mathrm{HNO}_{3}$. All the three supernatants were combined and dispersed in equal volumes of 2-propanol to precipitate the pectin, and allowed to settle for about $4 \mathrm{~h}$. The precipitate was collected, centrifuged, dispersed in 2-propanol, stirred for $30 \mathrm{~min}$ and centrifuged. This was repeated one more time with 2-propanol and, finally, with $70 \%$ 2-propanol. The sediment was dispersed in a small amount of water and freeze dried. The pectin obtained by sequential extraction and the total pectin extracts were each subjected to the following analyses.

The water soluble pectin fraction of dietary fibers was extracted with water, with phosphate buffer $(\mathrm{pH} 4.8)$ or with $0.01 \mathrm{~N}$ Phosphoric acid. This method was developed for identifying (WSP) pectin fraction with $0.01 \mathrm{~N}$ Phosphoric acid. The fiber $(0.2 \mathrm{~g})$ were dispersed in $100 \mathrm{ml}$ of $0.01 \mathrm{~N}$ Phosphoric acid and stirred for $1 \mathrm{~h}$ at room temperature. The supernatant was collected, and the sediment was extracted twice more in $0.01 \mathrm{~N}$ Phosphoric acid. All the three supernatants were combined, centrifuged. Combined supernatants, after centrifugation were concentrated in a rotary evaporator and then the supernatants were each subjected to the following analyses.

HPLC apparatus. An Agilent 1100 HPLC system (Agilent Technologies, Palo Alto CA-USA) operated by Windows NT based ChemStation software was used The HPLC equipment was used with a diode array detector (DAD). System consisted of a binary pump, degasser and auto sampler. The column used was a C610H: $7.8 \mathrm{~mm} \times 300 \mathrm{~mm}$. The ultra-violet spectra (scanning from $190 \mathrm{~nm}$ to 400 $\mathrm{nm}$ ) were recorded for all peaks.

High-performance liquid chromatography method. In addition to the gravimetric and other determinations of WSP and AIP were analyzed by the high-performance liquid chromatography method (HPLC). Solutions of samples were filtered through a $0.22 \mu \mathrm{m}$ pore size membrane filter before injection to chromatography analysis. The HPLC (Ravin, Gnanasambandam, Proctor, A, 1999) was modified for identifying pectin. The HPLC was used to determine galacturonic acid content and pectin of the fiber. D-galacturonic acio monohydrate and polygalacturonic acid (Sigma) was used as standard. All the standard solutions underwent the same type of treatment (were filtered through a $0.22 \mu \mathrm{m}$ disposable filter disk). Phosphoric acid $(0.01 \mathrm{~N})$ with a flow rate 0.70 $\mathrm{ml} / \mathrm{min}$ was used as the mobile phase. Ten $\mu \mathrm{l}$ of samples were injected and the detection wavelength was $210 \mathrm{~nm}$. The identification of compounds was achieved by comparing their UV spectra and retention times of separated peaks with retention times of standards. For comparison of retention times of galacturonic acid, polygalacturonic acid and pectin with pure standards of organic acids the flow rate of $0.5 \mathrm{ml} / \mathrm{min}$ and $0.7 \mathrm{ml} / \mathrm{min}$ was used.

Composition was determined as total uronic acids (galacturonic acid content) (Selvendran et al., 1979) and degree of methyl-esterification (DME) of pectin polysaccharides by the method described by Femenia et al. (1999) was expressed as percent methoxy groups. In addition to these methods composition was determined as total uronic acids (galacturonic acid content) and degree of methylesterification (DME) of pectin polysaccharides by the titration method described by Nelina, V.V. and et al. using a conductivity meter (Nelina, V., V. et al., 1992; Ignatieva, G., N., 2001).

The molecular weight was determined as the intrinsic viscosity by the method described by Nelina, V.V. and et al. (1992), where " $a$ " should go to 1.22 and $K=1.1 \times 10^{-5}$

Statistical analysis. All measurements were performed in triplicates and the values were averaged and reported along with the standard deviation $( \pm$ S.D) Multivariate analysis of data was performed by using Stat graphics V.7.1 program.

\section{RESULTS AND DISCUSSION}

The dietary fibers. It has been established that properties of dietary fibers depend on the ratio of soluble and insoluble parts and on the pectin content. The structure of dietary fibers has an influence on their chromatographic behavior. To investigate the influence of different structural features of fibers on its chromatographic behavior the dietary fibers were obtained from peel, "frit", "core" of dry and fresh lemons and of fresh oranges by using different technologies ("A" and "B"). Dry fiber samples were crushed to a powder of particle size $0.10 \div 0.25 \mathrm{~mm}$. According to results of the investigation the dietary fibers can be divided in to two groups. In the first groups, the content of AIP is approximately equal to fruit's content and in the second groups it is significantly low. The following samples of fiber obtained by the technology "A" are corresponded to the first group, having a relatively higher content of insoluble pectin fraction. In this work, the content of AIP in the dietary fibers was studied, compared with the content of WSP. The fiber samples obtained by the technology "B" are corresponded to the second group. The selected samples contain $18.3 \div 37.1 \%$ of WSP and $10.7 \div 23.1 \%$ of AIP.

Pectin fractions of dietary fibers were extracted with water (or with phosphate buffer, $\mathrm{pH} 4.8$ ) and with $0.1 \mathrm{~N} \mathrm{HNO}_{3}$. Data on the aqueous extraction and acid extraction are presented in the table 1 . Table 1 shows the comparative content of galacturonic acid, methoxyl groups (DME) in the water soluble pectin fraction and in the insoluble pectin fraction and molecular weight of both these pectin fractions. Analysis of this table demonstrates that the content of galacturonic acid was in the range $32.5 \div 46.6 \%$ and $23.5 \div 74.7 \%$, respectively for WSP and AIP. The content of methoxyl groups (DME) was $6 \div 25.8 \%$ in the case of WSP and $24.6 \div 38.7 \%$ in AIP. The molecular weight of WSP and AIP was in the range $5 \div$ $48 \mathrm{KDa}$ and $19 \div 70 \mathrm{KDa}$, respectively.

Table 1 Galacturonic acid, methoxyl group content and molecular weight of the water soluble pectin fraction and insoluble pectin fraction

\begin{tabular}{|c|c|c|c|c|}
\hline Solution & Pectin fraction & Galacturonic acid content, $\%$ & Molecular weight, KDa & $\begin{array}{c}\text { Degree of esterification } \\
\text { (DME) } \%\end{array}$ \\
\hline \multirow[t]{5}{*}{ Aqueous extraction } & Water soluble & 32.5 & 5 & 17.0 \\
\hline & & 41.6 & 39 & 6.00 \\
\hline & & 46.6 & 40 & 16.0 \\
\hline & & 38.8 & 48 & 23.6 \\
\hline & & 45.5 & 17 & 25.8 \\
\hline \multirow[t]{5}{*}{ Acid extraction } & Insoluble & 23.5 & 70 & 31.8 \\
\hline & & 29.8 & 26 & 27.5 \\
\hline & & 32.0 & 21 & 24.6 \\
\hline & & 74.7 & 19 & 32.4 \\
\hline & & 57.2 & 30 & 38.7 \\
\hline
\end{tabular}

The HPLC analyses galacturonic acid. The dietary fibers obtained in our laboratories and its aqueous and acid pectin extractions have been applied to develop the HPLC as a reliable analytical method. Numerous studies have been reported on the size exclusion chromatography analysis of homogeneity (polydispersity) of pectin and polygalacturonic acid using modes of detection including refractive index, ultraviolet absorption, laser light scattering, and viscometry (L. Cheng et.al., 1997; M.L. Fishman et.al., 1984; P.D. Hoagland et.al., 1993; D. Hourdet et.al., 1991; H.G. Barth, 1980). Our focus was to develop a simple, reproducible, and high-performance chromatography (HPLC) method using mode of ultraviolet absorption which allowed rapid screening of commercially available polygalacturonic acid raw materials and the pectin fraction. To develop this method, it was needed to study UV-absorbance of galacturonic acid and relationship between its concentration and UV- absorbance The aqueous solution (buffer, $\mathrm{pH} 4$.8) was selected for estimation, therefor was scanned in the wavelength range $190 \div 400 \mathrm{~nm}$. The spectrum showed a welldefined peak. The UV spectrum investigations demonstrated a singlet of maximum absorbance between wavelengths $190 \mathrm{~nm}$ and $208 \mathrm{~nm}$ corresponding to the purified galacturonic acid. This peak can be attributed to the galacturonic acid or its derivative. As was observed, the position of spectral maxima presented in the region around $190 \mathrm{~nm}$ is changed to wavelength $208 \mathrm{~nm}$ by increasing concentration of galacturonic acid. The results of UV spectrum demonstrated the linearity relationship between the concentration and UV-absorbance with high correlation 0.996 which was maintained over the concentration range of $0.04 \div 0.25 \% \mathrm{~g} / \mathrm{ml}$ (mass/volume percentage, \%w/v) for galacturonic acid (Fig 1). 


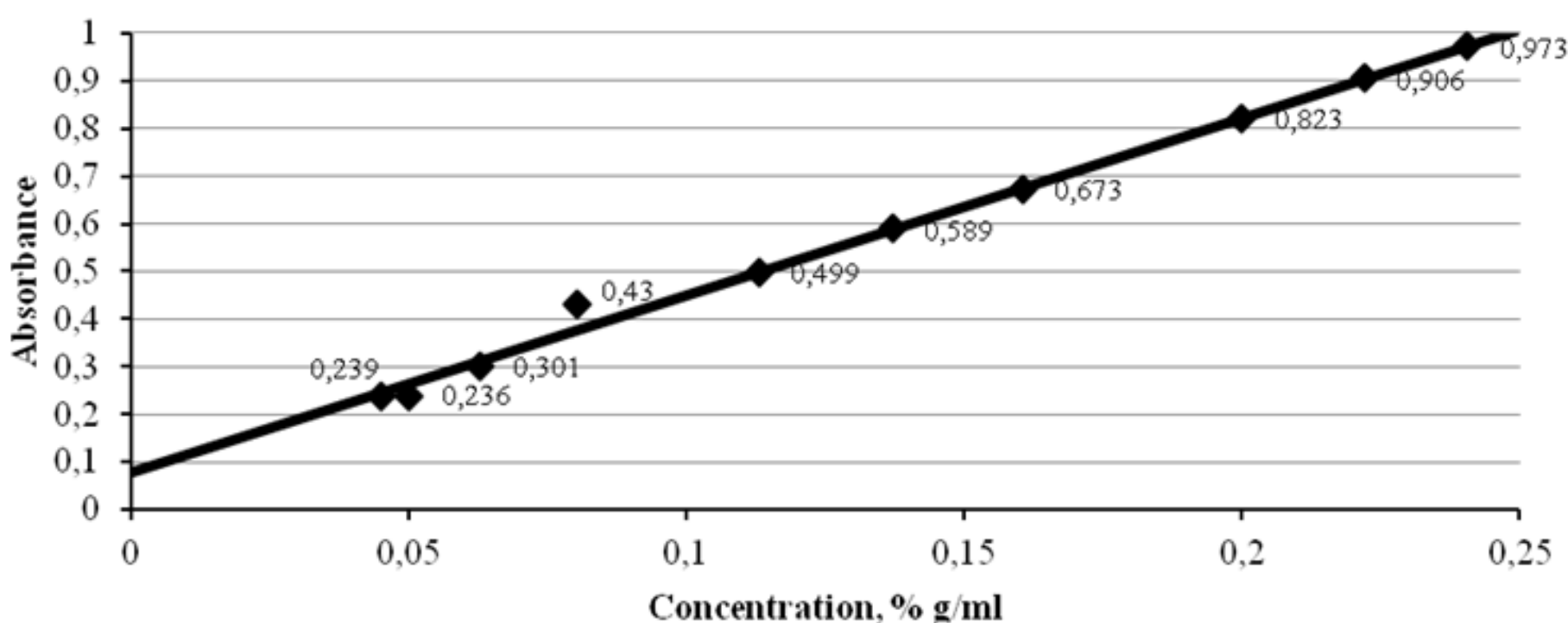

Figure 1 Relationship between the concentration of galacturonic acid and UV- absorbance at $210 \mathrm{~nm}$ measured by using UV spectrophotometric method.

Chromatographic analyses of organic acids, based on the method described by Chen, En, and Zhang were carried out using the HPLC equipped with UV detection at wavelength $214 \mathrm{~nm}$ (Chen, Z. G. et. al.,2006) $265 \mathrm{~nm}$ (Sara, C. Cunha et.al., 2002) and $210 \mathrm{~nm}$, as was done in this study. It can be concluded that this method may be used with the detection at the same wavelength $(210 \mathrm{~nm})$ for galacturonic acid.

The HPLC elution of galacturonic acid standard at $0.7 \mathrm{ml} / \mathrm{min}$ resulted in two peaks in the region $5 \div 9$ min (data not showed). It was observed that the area of second peak is increased from $145.550 \mathrm{mAU} \times \mathrm{s}$ to $3206.94 \mathrm{mAU} \times \mathrm{s}$ as the galacturonic acid content increased from $4.49 \times 10^{-2} \% \mathrm{~g} / \mathrm{ml}$ to $100.3 \times 10^{-2} \% \mathrm{~g} / \mathrm{ml}$ respectively. The elution profile (e. g. the area of this peak and its position) are independent of pectin excipients, of polygalacturonic excipients. Thus the retention time of the second peak may be used to identify the galacturonic acid Data of the HPLC chromatograms of galacturonic acid (the retention time, the area of peaks and the corresponded concentration of standard solutions) are presented in the table 2 and figure $2 \mathrm{~A}$.

Table 2 Data of the HPLC chromatograms of galacturonic acid

\begin{tabular}{llll}
\hline No. & $\mathrm{t}^{*}, \mathrm{~min}$ & Concentration of galacturonic acid, ${ }^{*}$ & Area of peak,*** \\
\hline 1 & 8.528 & $4.49 \times 10^{-2}$ & 145.550 \\
\hline 2 & 8.526 & $5.00 \times 10^{-2}$ & 202.960 \\
\hline 4 & 8.524 & $6.28 \times 10^{-2}$ & 254.100 \\
\hline 5 & 8.522 & $8.02 \times 10^{-2}$ & 292.320 \\
\hline 6 & 8.543 & $8.97 \times 10^{-2}$ & 436.890 \\
\hline 7 & 8.546 & $13.46 \times 10^{-2}$ & 505.660 \\
\hline 8 & 8.532 & $16.04 \times 10^{-2}$ & 762.280 \\
\hline 9 & 8.541 & $24.0610^{-2}$ & 1021.10 \\
\hline 10 & 8.550 & $32.08 \times 10^{-2}$ & 1290.43 \\
\hline 11 & 8.561 & $40.10 \times 10^{-2}$ & 1460.66 \\
\hline 12 & 8.573 & $44.83 \times 10^{-2}$ & 1567.41 \\
\hline 13 & 8.568 & $48.12 \times 10^{-2}$ & 1815.34 \\
\hline 14 & 8.585 & $56.14 \times 10^{-2}$ & 2117.83 \\
\hline 15 & 8.590 & $64.17 \times 10^{-2}$ & 2583.52 \\
\hline 16 & 8.603 & $80.21 \times 10^{-2}$ & 3206.94 \\
\hline Legend:*Retention time $(\mathrm{t}) ; *$ Concentration of galacturonic acid, \% $/ \mathrm{ml} ; * *$ Area of peak, mAU x s.
\end{tabular}

All values are corresponded to the mean of three replicated determinations. This table are illustrated that the retention time of galacturonic acid was in the range of minimum 8.522 min to maximum $8.619 \mathrm{~min}$. According to the retention time of standard organic acids, the peak around $8.557 \mathrm{~min}$ can be attributed to galacturonic acid. Data of statistical analysis of the retention time for galacturonic acid standard solutions are presented in the table 3.
The differences in the retention time of galacturonic acid were not statistically significant having the mean, standard deviation (std.dev), standard error (std. error) and confidence interval of mean (C.I. of means): $8.557 \pm 3.01 \times 10^{-2} ; 0.752$ $\times 10^{-2}$ and $1.600 \times 10^{-2}$, respectively. However, it was observed that a change of the galacturonic acid concentration in standard solutions from $4.49 \times 10^{-2} \% \mathrm{~g} / \mathrm{ml}$ to $100.3 \times 10^{-2} \% \mathrm{~g} / \mathrm{ml}$ (Tab 2) might result in differences of retention times between standard samples. The results are summarized in figure $3 \mathrm{~A}$.

Table 3 Data of statistical analysis

\begin{tabular}{|c|c|c|c|c|c|c|}
\hline Mean & $\mathrm{SD}^{*}$ & SEM* $^{*}$ & C.I. of mean $*$ & Range & Maximum & Minimum \\
\hline \multicolumn{7}{|c|}{ Galacturonic acid } \\
\hline 8.557 & $3.010 \times 10^{-2}$ & $0.752 \times 10^{-2}$ & $1.600 \times 10^{-2}$ & $9.708 \times 10^{-2}$ & 8.619 & 8.522 \\
\hline \multicolumn{7}{|c|}{ Polygalacturonic acid, at $0.7 \mathrm{ml} / \mathrm{min}$} \\
\hline 5.600 & $0.323 \times 10^{-2}$ & $0.108 \times 10^{-2}$ & $0.248 \times 10^{-2}$ & $0.900 \times 10^{-2}$ & 5.605 & 5.596 \\
\hline \multicolumn{7}{|c|}{ Polygalacturonic acid, at $0.5 \mathrm{ml} / \mathrm{min}$} \\
\hline 7.851 & $0.748 \times 10^{-2}$ & $0.283 \times 10^{-2}$ & $0.692 \times 10^{-2}$ & $2.000 \times 10^{-2}$ & 7.858 & 7.836 \\
\hline
\end{tabular}

Legend:*Confidence interval of mean (C.I. of mean); Standard Deviation (Std.dev. or SD); Standard Error (Std. error or SEM). 
In general the value of retention time for standard solution having $100.3 \times 10$ ${ }^{2} \% \mathrm{~g} / \mathrm{ml}$ galacturonic acid was slightly higher $(8.619 \mathrm{~min})$ than for standard solution having $24.06 \times 10^{-2} \% \mathrm{~g} / \mathrm{ml}$ galacturonic acid $(8.541 \mathrm{~min})$ and $4.49 \times 10^{-}$ ${ }^{2} \% \mathrm{~g} / \mathrm{ml}$ galacturonic acid $(8.528 \mathrm{~min})$ but these differences are less than $<<0.5$ min. The relative precision of methods is compared by calculating their percent relative standard deviation. The relative standard deviation of galacturonic acid qualification at $0.7 \mathrm{ml} / \mathrm{min}$ flow rate is $0.35 \%$.
For rapid identification and quantification of galacturonic acid the calibration curve was constructed to quantify the composition in real samples with the aid of this curve. The calibration curve of pure standard was constructed by triplicate determinations of each 16 concentrations (Tab 2). The relationship between galacturonic acid content and peak area revealed a straight line with the correlation coefficient of 0.9997 . Data were fitted to the equation $Y=3227.8 \mathrm{X}-$ 0.3211 where " $\mathrm{Y}$ " is the peak area and " $\mathrm{X}$ " is concentration in \% $\mathrm{g} / \mathrm{ml}$ (Fig 4A)
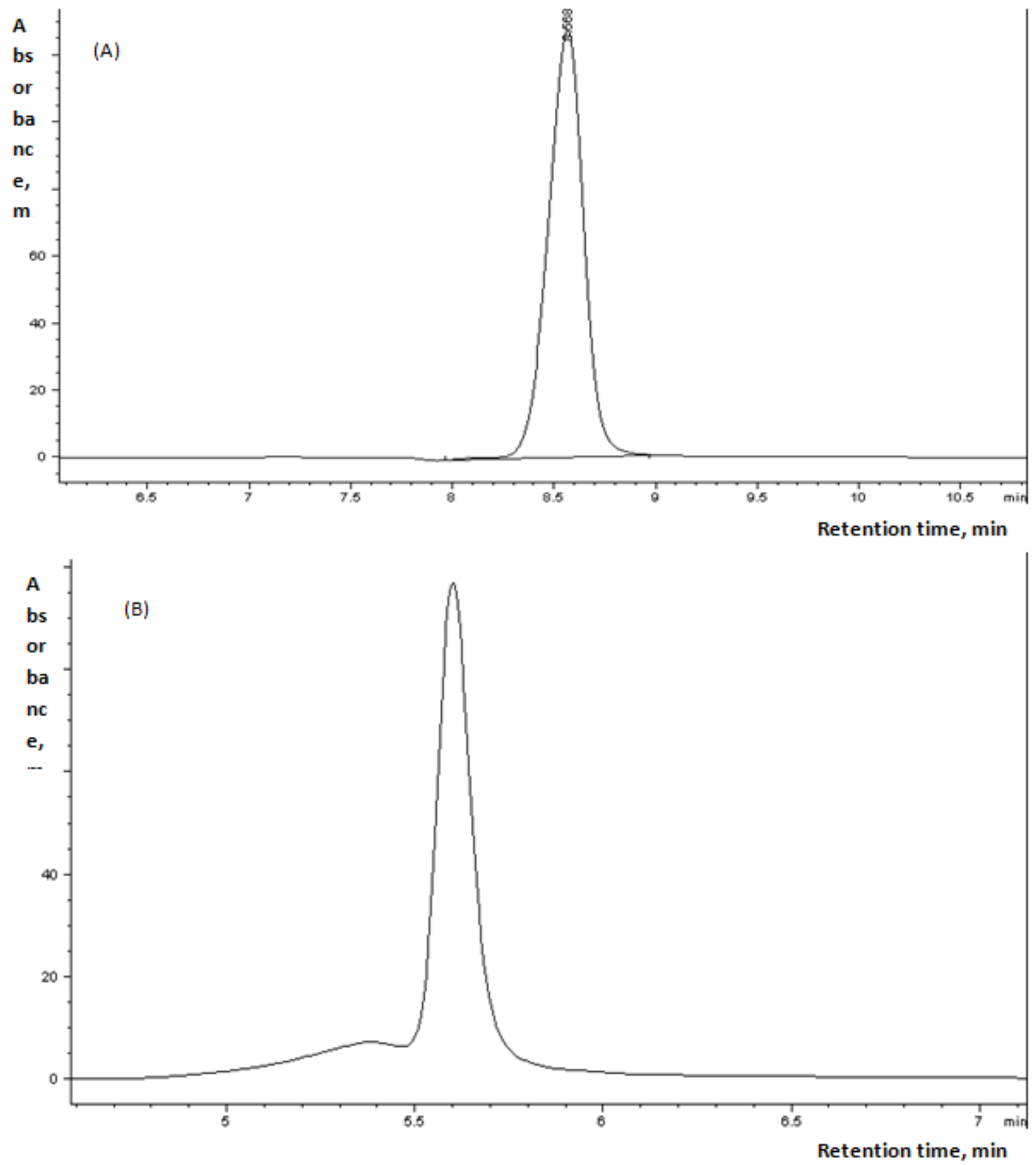

Figure 2 HPLC chromatograms of standard galacturonic acid (A) and standard polygalacturonic acid (B) solutions. 
- Retention time $\rightarrow-$ Maximummeans - -Average means $\square$ - Minimummeans


Figure 3 The correlation between the retention time and the content of standard galacturonic acid (A), standard polygalacturonic acid (B) and water soluble pectin fraction $(\mathrm{C})$ in solutions.

The slope is 3227.8 and the $\mathrm{Y}$ - intercept is (-0.3211). This linearity was maintained over the concentrations range of $0.04 \div 1.00 \% \mathrm{~g} / \mathrm{ml}$. The value of LOQ (Huber, $\mathrm{L}$. 1998) was found as 0.0042 for proposed method. 


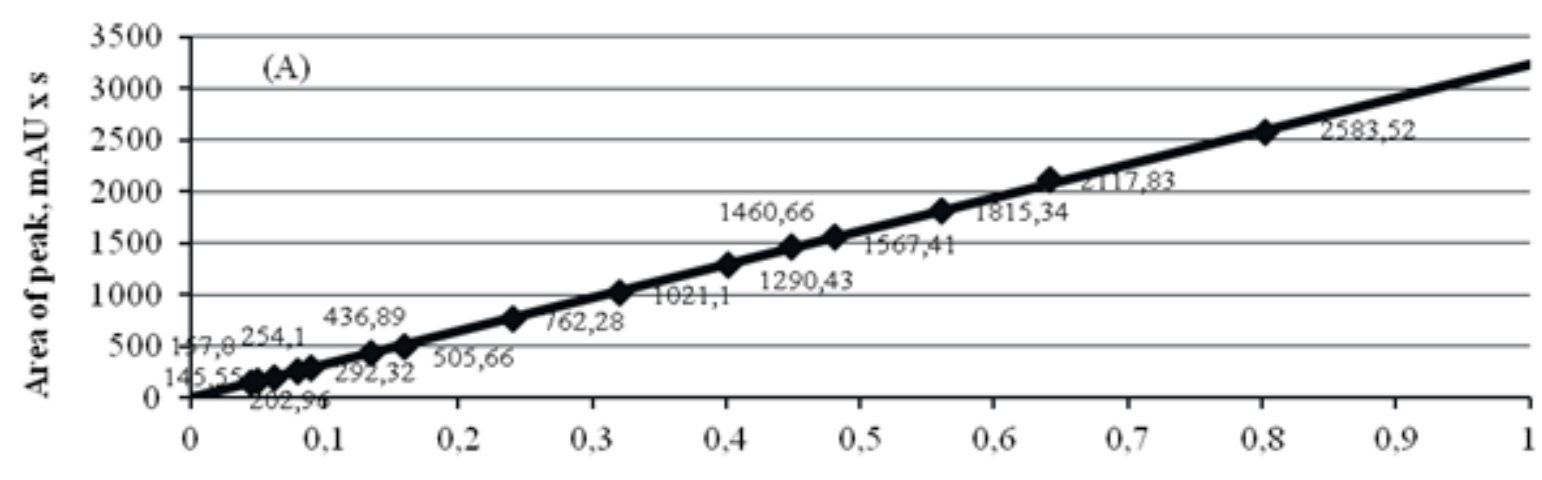

Concentration, $\% \mathrm{~g} / \mathrm{ml}$

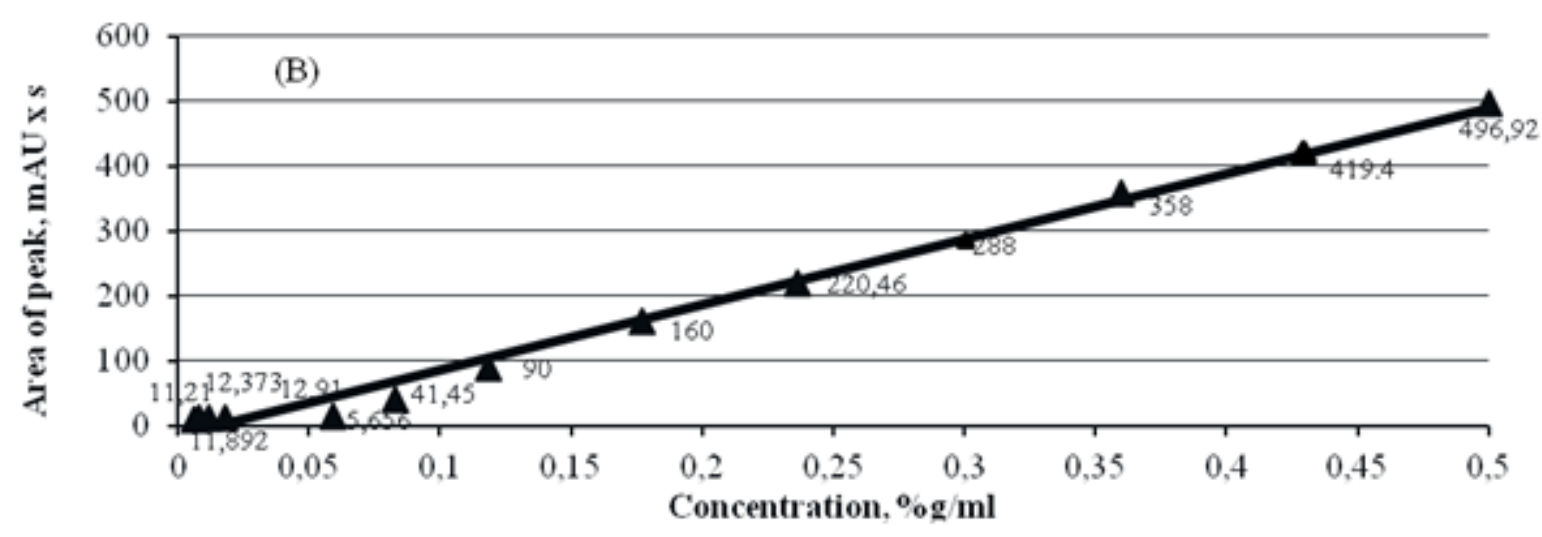

Figure 4 The calibration plots for galacturonic acid (A) and polygalacturonic acid (B).

The line equation and standard deviations obtained for the UV spectrophotometric method were compared to those obtained for the HPLC method. The calibration curve of UV spectrophotometric method of the galacturonic acid had features $Y=3.7289 \mathrm{X}+0.0778$, the correlation coefficient of 0.996 similar to the calibration curve of HPLC chromatogram $Y=$ $32227.8 \mathrm{X}-0.3211$ (Fig 1; 4A). It should be noted that the chromatographic analysis was carried out using the bigger concentration range $(0.04 \div 1.00 \% \mathrm{~g} / \mathrm{ml})$ than the UV spectrophotometric method $(0.04 \div 0.25 \% \mathrm{~g} / \mathrm{ml})$.

The HPLC analyses polygalacturonic acid. To determine the detection parameters of the polygalacturnic acid by HPLC method its spectroscopic properties at $190 \div 400 \mathrm{~nm}$ were studied. In agreement with the chemical analysis, the UV spectrum of polygalacturoic acid clearly shows the typical signal pattern expected for this structure moiety. There were two peaks in the spectrum. Peaks were equal in shape and different in intensity. Absorption in the UV region is mainly caused by electronic transition of bonds. These signals of polygalacturonic acid at $200 \mathrm{~nm}, 254 \mathrm{~nm}$ are corresponded to the $\pi-\pi$ and $\mathrm{n}-\pi$ of electronic transitions, respectively. The dominant absorption at $200 \mathrm{~nm}$ was attributed to the $\pi-\pi$ of electronic transitions. Therefore, it can be concluded that the detection at wavelength $210 \mathrm{~nm}$ could be preferable for polygalacturonic acid as for galacturonic acid. The chromatographic behavior of standard solutions was studied by using the flow rate $0.5 \mathrm{ml} / \mathrm{min}$ (a) and $0.7 \mathrm{ml} / \mathrm{min}$ (b). Data HPLC chromatograms of standard solutions of the polygalacturonic acid are presented in the table 4 (retention times, the area of peaks).

Table 4 The chromatographic behavior of polygalacturonic acid standard solutions

\begin{tabular}{|c|c|c|c|c|c|c|}
\hline \multirow[t]{3}{*}{ No. } & \multicolumn{4}{|l|}{ Flow rate $b^{*}$} & \multicolumn{2}{|l|}{ Flow rate $\mathrm{a}^{*}$} \\
\hline & Peak 1 & & Peak 2 & & Peak 1 & \\
\hline & Retention time, min & $\begin{array}{l}\text { Area, } \\
\text { mAU x s }\end{array}$ & $\begin{array}{l}\text { Retention time, } \\
\text { min }\end{array}$ & $\begin{array}{l}\text { Area, } \\
\text { mAU x s }\end{array}$ & Retention time, min & $\begin{array}{l}\text { Area, } \\
\text { mAU x s }\end{array}$ \\
\hline 1 & 5.602 & 11.210 & $\mathrm{n}$ & $\mathrm{n}$ & 7.858 & 15.030 \\
\hline 2 & 5.605 & 11.892 & $\mathrm{n}$ & $\mathrm{n}$ & 7.856 & 16.060 \\
\hline 3 & 5.603 & 12.910 & $\mathrm{n}$ & $\mathrm{n}$ & 7.854 & 17.530 \\
\hline 4 & 5.603 & 12.379 & $\mathrm{n}$ & $\mathrm{n}$ & 7.854 & 17.070 \\
\hline 5 & 5.599 & 15.656 & $\mathrm{n}$ & $\mathrm{n}$ & 7.849 & 23.030 \\
\hline 6 & 5.596 & 34.870 & $\mathrm{n}$ & $\mathrm{n}$ & 7.836 & 56.930 \\
\hline 7 & 5.598 & 496.92 & 8.009 & 77.033 & 7.847 & 668.29 \\
\hline
\end{tabular}

The samples used for calibration curve were also used to determine relationship between the retention time of polygalacturonic acid and the flow rate of mobile phase; the retention time of polygalacturonic acid and the concentration in standard solutions; the peak area and the flow rate of mobile phase.

The mixtures of pectin, polygalacturonic acid and other organic acids resulted in low resolution of the chromatographic separation at $0.5 \mathrm{ml} / \mathrm{min}$ that usually is used for the analysis of organic acids and neutral sugars, thereby making complexity the identification and quantification of the polygalacturonic acid and pectin at this flow rate. The polygalacturonic acid is eluted at $7.851 \mathrm{~min}$ by using $0.5 \mathrm{ml} / \mathrm{min}$ (std.dev, std. error and C.I. of means are $0.748 \times 10^{-2} ; 0.283 \times 10^{-2}$ and $0.692 \times 10^{-2}$, respectively) (Tab 3). Series of chromatograms of WSP and AIP showed two peaks at $7.980 \mathrm{~min}$ (std.dev, std. error and C.I. of means are $4.60 \times 10^{-2} ; 0.939 \times 10^{-2}$ and $1.94 \times 10^{-2}$, respectively), $8.747 \mathrm{~min}$ (std.dev, std. error and C.I. of means are $20.8 \times 10^{-2} ; 4.43 \times 10^{-2}$ and $9.21 \times 10^{-2}$, respectively) or one peak at $7.980 \mathrm{~min}$ by using the same $0.5 \mathrm{ml} / \mathrm{min}$ flow rate (Tab 5). 
Table 5 Data of statistical analysis of retention time both water soluble pectin and insoluble pectin fraction

\begin{tabular}{lllllllll}
\hline$*$ & $* *$ & Mean & SD & SEM & C.I. of mean & Range & Maximum & Minimum \\
\hline 1 & $\mathrm{a}$ & 7.980 & $4.60 \times 10^{-2}$ & $0.939 \times 10^{-2}$ & $1.94 \times 10^{-2}$ & 0.236 & 8.160 & 7.924 \\
\hline 2 & $\mathrm{a}$ & 8.748 & $20.8 \times 10^{-2}$ & $4.430 \times 10^{-2}$ & $9.21 \times 10^{-2}$ & 0.994 & 9.001 & 8.007 \\
\hline 1 & $\mathrm{~b}$ & 5.615 & $3.55 \times 10^{-2}$ & $0.725 \times 10^{-2}$ & $1.50 \times 10^{-2}$ & 0.149 & 5.702 & 5.553 \\
\hline 2 & $\mathrm{~b}$ & 5.855 & $16.2 \times 10^{-2}$ & $4.340 \times 10^{-2}$ & $9.38 \times 10^{-2}$ & 0.621 & 6.418 & 5.797 \\
\hline
\end{tabular}

Legend:* Number of peaks. ** The separation was performed on a C610H column. The flow rate was $0.5 \mathrm{ml} / \mathrm{min}(\mathrm{a})$ and $0.7 \mathrm{ml} / \mathrm{min}$ (b).

Additionally, evaluating of the method's precision for 3 days the HPLC separation of WSP and AIP are confirmed two peaks at 7.968 min (average), $8.788 \mathrm{~min}$ (average) or one peak at $7.968 \mathrm{~min}$ (average). The elution profiles of both runs were identical. The HPLC chromatogram of the following compounds (citric, isocitric, malic lactic, tartaric and ascorbic acids) showed the peaks of chromatographic profile in the range from $9.00 \mathrm{~min}$ to $21.71 \mathrm{~min}$ on the $210 \mathrm{~nm}$.
The retention times of different organic acids were identified by comparison of their retention times with those of pure standards of other workers (Supelco Sigma-Aldrich Quimica, S.A. 2001). Finally, the peak of oxalic acid (9.06 min) located close to peak ranges of WSP and AIP $7.924 \div 8.160$ min and $7.978 \div 8.017$ and to $9.001 \mathrm{~min}$, respectively (Tab 6; 7).

Table 6 The chromatographic behavior of water soluble pectin and insoluble pectin fractions (fresh raw material)

\begin{tabular}{|c|c|c|c|c|c|c|c|}
\hline No.** & Part of fruit & Solution & Flow rate $*$ & \multicolumn{2}{|l|}{ Peak 1} & \multicolumn{2}{|l|}{ Peak 2} \\
\hline 1 & Frit & \multirow{11}{*}{$\begin{array}{l}\text { Aqueous } \\
\text { extraction }\end{array}$} & $\mathrm{a}$ & 7.961 & 65.340 & 8.787 & 20.040 \\
\hline 3 & \multirow[t]{3}{*}{ Core } & & $\mathrm{a}$ & 7.961 & 77.020 & 8.786 & 17.000 \\
\hline 4 & & & $\mathrm{~b}$ & 5.595 & 57.520 & 5.797 & 10.200 \\
\hline 5 & & & $\mathrm{a}$ & 7.959 & 81.310 & $\mathrm{n}$ & $\mathrm{n}$ \\
\hline 8 & Peel & & $\mathrm{b}$ & 5.589 & 152.69 & 5.821 & 54.020 \\
\hline 9 & \multirow[t]{4}{*}{ Frit } & & $\mathrm{a}$ & 7.924 & 238.95 & 8.790 & 102.20 \\
\hline 10 & & & $\mathrm{~b}$ & 5.553 & 182.02 & 5.823 & 69.590 \\
\hline 11 & & & $\mathrm{a}$ & 7.947 & 150.77 & 8.788 & 40.190 \\
\hline 12 & & & $\mathrm{~b}$ & 5.574 & 113.78 & 5.821 & 25.280 \\
\hline 17 & \multirow[t]{8}{*}{ Peel } & & $\mathrm{a}$ & 8.024 & 71.750 & 8.938 & 14.860 \\
\hline 18 & & & $\mathrm{~b}$ & 5.609 & 37.670 & 5.833 & 17.870 \\
\hline 19 & & \multirow{6}{*}{ Acid extraction } & $\mathrm{a}$ & 8.017 & 65884 & 8.302 & 15575 \\
\hline 20 & & & $\mathrm{~b}$ & 5.669 & 52640 & $\mathrm{n}$ & $\mathrm{n}$ \\
\hline 21 & & & $\mathrm{a}$ & 8.004 & 70278 & 8.845 & 3158.32 \\
\hline 22 & & & $\mathrm{~b}$ & 5.701 & 50623 & $\mathrm{n}$ & $\mathrm{n}$ \\
\hline 23 & & & $\mathrm{a}$ & 7.998 & 99801 & 8.635 & 14198 \\
\hline 24 & & & $\mathrm{~b}$ & 5.702 & 74931 & $\mathrm{n}$ & $\mathrm{n}$ \\
\hline
\end{tabular}

Legend:* The flow rate was $0.5 \mathrm{ml} / \mathrm{min}$ (a) and $0.7 \mathrm{ml} / \mathrm{min}$ (b). **Dietary fibers the No.1-16 were produced by using the technology "A", the No.17-24 were produced by using the technology "B", the No.1-6 were produced from orange raw material, the No.7-24 were produced from lemon raw material. *** Area of peak, mAU x s. $\mathrm{n}-$ No isolates.

Table 7 The chromatographic behavior of water soluble and insoluble pectin fractions of dietary fibers** (lemon dry raw material, peel dry)

\begin{tabular}{|c|c|c|c|c|c|c|}
\hline \multirow[t]{2}{*}{ No. } & \multirow[t]{2}{*}{ Solution } & \multirow{2}{*}{$\begin{array}{l}\text { Flow rate } \\
*\end{array}$} & \multicolumn{2}{|l|}{ Peak 1} & \multicolumn{2}{|l|}{ Peak 2} \\
\hline & & & $\mathrm{t}, \min$ & Area, mAU x s & $\mathrm{t}, \mathrm{min}$ & Area, mAU x s \\
\hline 1 & \multirow{12}{*}{$\begin{array}{l}\text { Aqueous } \\
\text { extraction }\end{array}$} & $\mathrm{a}$ & 8.160 & 64.770 & 9.001 & 47.890 \\
\hline 2 & & $\mathrm{~b}$ & 5.601 & 31.560 & 5.803 & 51.060 \\
\hline 3 & & $\mathrm{a}$ & 7.955 & 44.560 & 8.803 & 56.340 \\
\hline 4 & & $\mathrm{~b}$ & 5.599 & 32.800 & 5.803 & 51.940 \\
\hline 5 & & $\mathrm{a}$ & 7.968 & 45.740 & 8.795 & 69.800 \\
\hline 6 & & $\mathrm{~b}$ & 5.600 & 29.560 & 5.803 & 40.380 \\
\hline 7 & & $\mathrm{a}$ & 7.964 & 49.350 & 8.794 & 107.240 \\
\hline 8 & & $\mathrm{~b}$ & 5.599 & 31.610 & 5.810 & 76.300 \\
\hline 9 & & $\mathrm{a}$ & 7.960 & 50.910 & 8.007 & 88.220 \\
\hline 10 & & $\mathrm{~b}$ & 5.601 & 25.760 & 5.809 & 60.210 \\
\hline 11 & & $\mathrm{a}$ & 7.968 & 54.780 & 8.805 & 96.560 \\
\hline 12 & & $\mathrm{~b}$ & 5.597 & 31.670 & 5.804 & 66.290 \\
\hline 13 & \multirow{11}{*}{ Acid extraction } & $\mathrm{a}$ & 7.978 & 44693 & 8.776 & 1181.33 \\
\hline 14 & & $\mathrm{~b}$ & 5.618 & 28109 & $\mathrm{n}$ & $\mathrm{n}$ \\
\hline 15 & & $\mathrm{a}$ & 7.984 & 62580 & 8.808 & 4830.15 \\
\hline 16 & & $\mathrm{~b}$ & 5.634 & 44304 & $\mathrm{n}$ & $-n$ \\
\hline 17 & & $\mathrm{a}$ & 7.987 & 64136 & 8.794 & 4142.81 \\
\hline 18 & & $\mathrm{~b}$ & 5.630 & 43187 & $\mathrm{n}$ & $\mathrm{n}$ \\
\hline 19 & & $\mathrm{a}$ & 7.988 & 63535 & 8.810 & 3980.65 \\
\hline 20 & & $\mathrm{~b}$ & 5.644 & 42776 & $\mathrm{n}$ & $\mathrm{n}$ \\
\hline 21 & & $\mathrm{a}$ & 7.931 & 56093 & 8.805 & 1133.46 \\
\hline 22 & & $\mathrm{~b}$ & 5.627 & 41114 & 6.418 & 3423.47 \\
\hline 23 & & $\mathrm{~b}$ & 5.648 & 61035 & $\mathrm{n}$ & $\mathrm{n}$ \\
\hline
\end{tabular}

Legend:* The flow rate was $0.5 \mathrm{ml} / \mathrm{min}$ (a) and $0.7 \mathrm{ml} / \mathrm{min}$ (b). **Dietary fibers were produced by using the technology "B". $\mathrm{n}-\mathrm{No}$ isolates.

This was the reason for seeking a flow rate of elution which would enable to achieve a suitable resolution of samples which being studied. For this purpose, the chromatographic separation was tested using $0.7 \mathrm{ml} / \mathrm{min}$ flow rate. The use
$0.7 \mathrm{ml} / \mathrm{min}$ allowed accelerated elution of the polygalacturonic acid. The chromatograms corresponding to polygalacturonic acid showed a peak to approximately at $5.6 \mathrm{~min}$ ( $\mathrm{Tab} 4)$. 
The direct analysis of polygalacturonic acid by HPLC does not have the potential problems but there have been considerable difficulties in the procedure optimized this analytical technique. The peak area was dependent of the flow rate of elution. The change of mobile phase flow from $0.5 \mathrm{ml} / \mathrm{min}$ to $0.7 \mathrm{ml} / \mathrm{min}$ resulted in the variation of retention time for polygalacturonic acid and significantly decreased of the peak area from $23.030 ; 56.930 ; 668.29$ to $15.656 ; 34.870 ; 496.92$, respectively (Tab 4). The use of flow-rate $0.5 \mathrm{ml} / \mathrm{min}$ can cause co-elution of pectin compounds and organic acids. Gregory W. White and et. al (1999) have been reported that since polygalacturonic acid is insoluble in acidic aqueous solutions, therefore for procedure optimized of the solvent system to be use a neutral buffered solution ( $50 \mathrm{mM}$ phosphate buffer, $\mathrm{pH}$ 6.9). It was suggested the first, that the most successful approach to use the HPLC has been via the change $\mathrm{pH}$ of the solvent system. The second, using flow-rate of $0.7 \mathrm{ml} / \mathrm{min}$, it was possible to obtain good quality chromatogram profile, injecting $10 \mu$ into the column $\mathrm{C} 610 \mathrm{H}$. The peak position of polygalacturonic acid in range 5.596: $5.605 \mathrm{~min}$ at $0.7 \mathrm{ml} / \mathrm{min}$ (Tab 4) was confirmed by HPLC analysis of this pure standard component (Fig 2B). The retention times not varied between different series, in contrast to series of galacturonic acid chromatograms. The mean of polygalacturonic acid retention times of HPLC chromatograms and data of its statistical analysis are presented in the table 3. The relative standard deviation, standard deviation, standard error and confidence interval of retention time were $0.06 \% ; 0.323 \times 10^{-2} ; 0.108 \times 10^{-2} ; 0.248 \times 10^{-2}$ respectively. The extent of deviations the polygalacturonic acid retention time is plotted as a function of concentration in order to determine the range, which can be assessed as a function of concentration. Deviations the retention time of standard solutions of polygalacturonic acid were between $5.596 \mathrm{~min}$ and $5.605 \mathrm{~min}$ for the $0.6 \div 50.0 \mathrm{x}$ $10^{-2} \% \mathrm{~g} / \mathrm{ml}$ concentrations (Fig 3B). Concentrations of standard solutions of polygalacturonic acid from $0.59 \times 10^{-2} \% \mathrm{~g} / \mathrm{ml}$ to $50.0 \times 10^{-2} \% \mathrm{~g} / \mathrm{ml}$ are corresponded to area of peaks from $11.210 \mathrm{mAU}$ x s to $496.92 \mathrm{mAU} \mathrm{x} \mathrm{s}$. Regression analysis showed a linear relationship between the peak area and the content of polygalacturonic acid. The calibration graph was constructed after analysis of 10 different concentrations with each concentration was measured three times. The fitted model was represented by the calibration equation: $Y=$ $1009.8 \mathrm{X}-14.774$ where " $\mathrm{Y}$ " is the peak area and " $\mathrm{X}$ " is the concentration in $\% \mathrm{~g} / \mathrm{ml}$ with the correlation coefficient of 0.99 (Fig 4B). The calibration graph of the area versus concentration was found to be linear over $1.7 \div 50.0 \times 10^{-2} \% \mathrm{~g} / \mathrm{m}$ range. The method's precision was demonstrated by evaluating concentration linearity of the calibration curve, on the same column, for 3 days. The coefficient of correlation was 0.999 for the three linear regression analyses.

The HPLC method for pectin substance analysis of dietary fibers. It is expected that the HPLC method established might also be useful for the direct determination of pectin fractions in dietary fibers. In this regard the identities of various constituents of all pectin fractions were verified by means of their retention times as well as by the comparison of their peaks to standard additions (polygalacturonic acid and galacturonic acid). The chromatograms corresponding to pure polygalacturonic acid gave one peak $(5.600 \mathrm{~min})$ at $1.7 \div 50.0 \times 10^{-2} \% \mathrm{~g} / \mathrm{ml}$ range. The chromatograms corresponding to pure galacturonic acid gave one peak $(8.557 \mathrm{~min})$ at $4.5 \div 100.0 \times 10^{-2} \% \mathrm{~g} / \mathrm{ml}$ range. Table 6 and 7 are illustrated the data of 24 samples of WSP and AIP by using flow rate $0.5 \mathrm{ml} / \mathrm{min}$ and 0.7 $\mathrm{ml} / \mathrm{min}$. The chromatograms corresponding to pectin fractions gave two peaks around $7.980 \mathrm{~min}$ and $8.748 \mathrm{~min}$ (data not showed); $5.615 \mathrm{~min}$ and $5.855 \mathrm{~min}$ (Fig 5A; B) by using $0.5 \mathrm{ml} / \mathrm{min}$ and $0.7 \mathrm{ml} / \mathrm{min}$ flow rate, respectively (Tab 5).

The statistical significance of retention times, the standard deviation, standard error, confidence interval of mean was determined for each of two flow rate (Tab 5). According to presented data of HPLC pectin fractions, the values of retention time for the first peak are between $5.553 \div 5.702 \mathrm{~min}$ (Tab 5) at $0.7 \mathrm{ml} / \mathrm{min}$ flow rate. The metrological characteristics of retention time of water soluble pectin fractions and insoluble pectin fractions were as follows: standard deviation $3.55 \mathrm{x}$ $10^{-2}$; standard error $0.725 \times 10^{-2}$. These values were the greater than metrological characteristics of retention time of polygalacturonic acid (standard error $0.108 \mathrm{x}$ $10^{-2}$ and standard deviation $0.323 \times 10^{-2}$ ) (Tab 3), but the relative standard deviation of retention time at a confidence probability of 0.95 does not exceed $0.63 \%$.

In classical HPLC the peak broadening, tailing, and considerable variability of absolute retention times are sometimes inevitable that may often reach up to $5 \%$ unless conditions are fully optimized. The tolerably small differences between the retention time of individual samples (Tab 6 and 7) may be attributed to slight differences in the column properties that occur during the relatively long recording time of the chromatogram and more may be attributed to differences in the pectin properties such as polydispersity. The chromatogram profile obtained for pectin solution in the presence of excipients was identical with that obtained for standard solution containing an equivalent concentration of pectin fraction indicating that the retention time and the area of peak don't change. It was concluded that the excipients did not interfere to quantification of pectin fractions in this method and the proposed method could be considered specific to determinate of the pectin. The ruggedness of the proposed method was evaluated by applying the developed procedures to assay of pectin fractions using the same instrument by two different analysts under the same optimized conditions at different days. The obtained results were found to be reproducible, since there was no significant difference between analysts (data not showed). Thus, the proposed method could be considered rugged. 


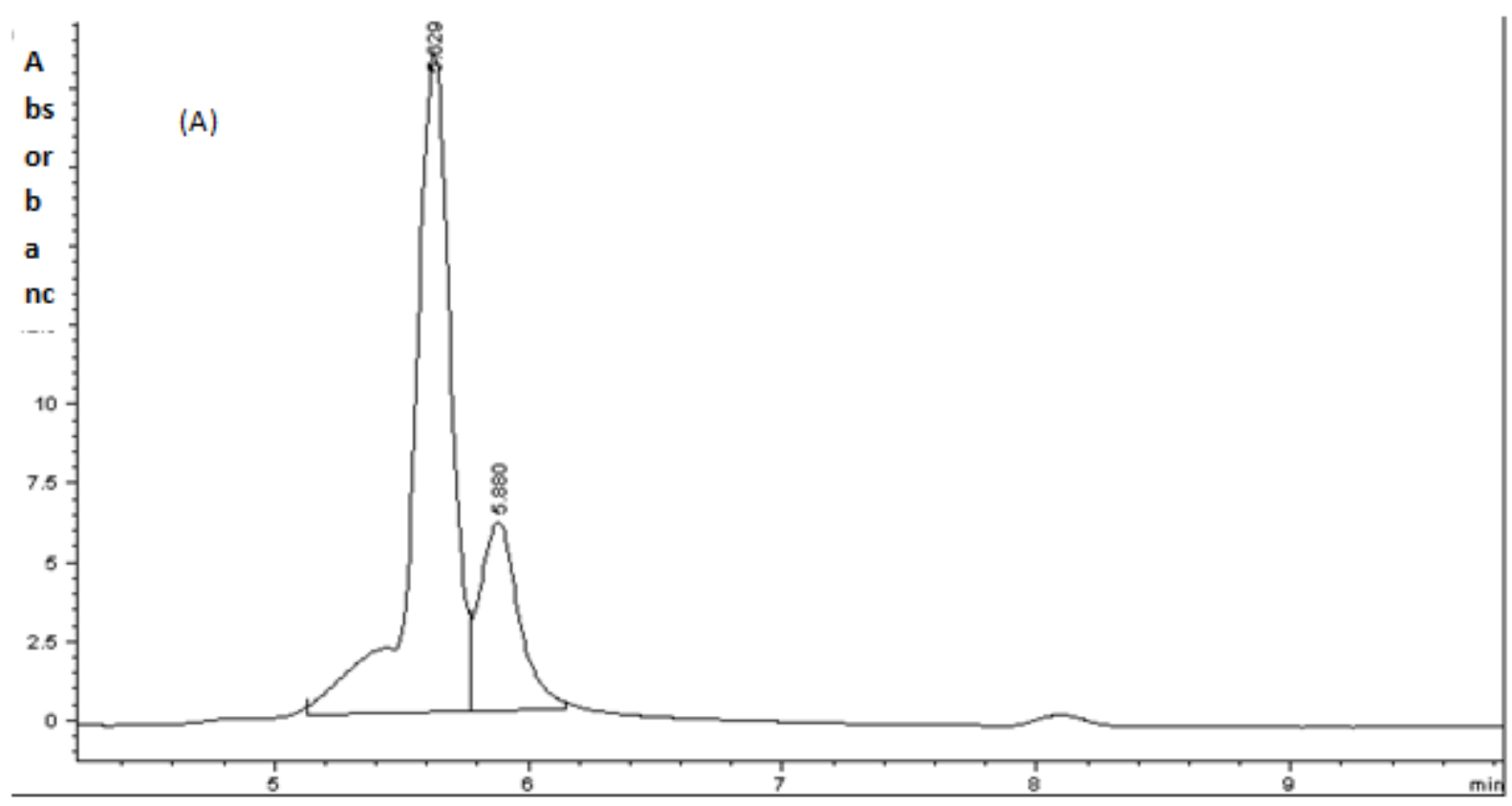

Retention time, $\min$

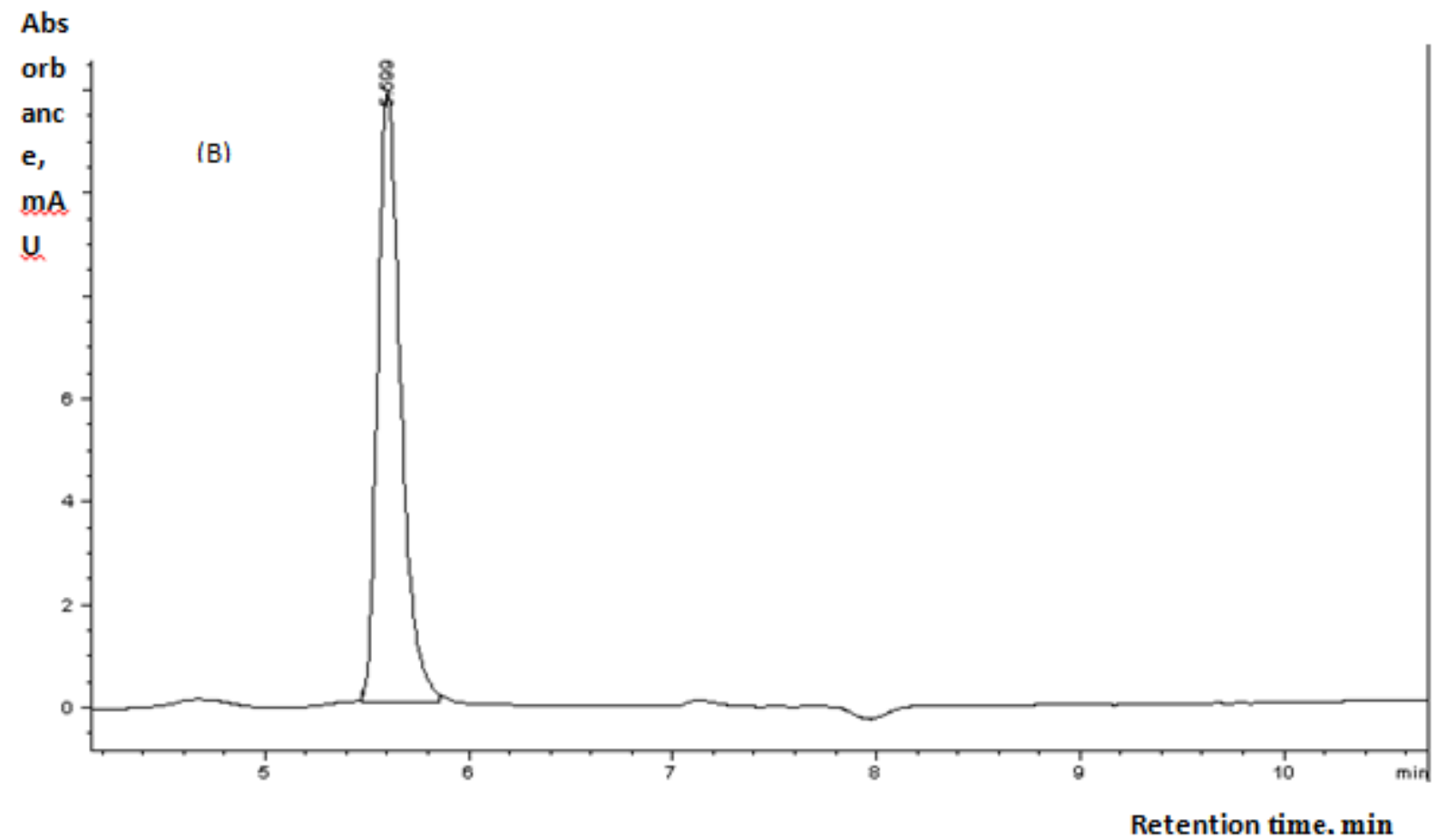

Figure 5 HPLC chromatograms of water soluble pectin solution (A) and insoluble pectin solution (was diluted to 1:316.3 ratios) (B).

Finally, the results from the cross validation were used to develop a final calibration model. The same statistical data of the mean of peak area, 95\% confidence intervals of means, standard deviation, standard error (SEM) and the average relative standard deviation of peak area between values of all relative standard deviations were calculated. The mean of presented area of each sample was determined by taking the average values of three replicate analyses. Data of statistical analysis of the peak area for pectin solutions are presented in the table 8 .

$\underline{\text { Table } 8 \text { Data of statistical analysis of area of peak at } 0,7 \mathrm{ml} / \mathrm{min} \text { both water soluble pectin and insoluble pectin fraction }}$

\begin{tabular}{llllllll}
\hline No. & Mean & SD & SEM & C.I. of mean & RSD, $\%$ & No. table & No. sample \\
\hline 1 & 79.800 & 3.510 & 2.026 & 8.719 & 4.40 & 10 & 16 \\
\hline 2 & 73.540 & 4.090 & 2.361 & 10.16 & 5.56 & 10 & 14 \\
\hline 3 & 62.577 & 7.666 & 4.426 & 19.04 & 12.25 & 10 & 6 \\
\hline 4 & 57.523 & 2.835 & 1.637 & 7.043 & 4.93 & 10 & 4 \\
\hline 5 & 56.808 & 0.929 & 0.536 & 2.307 & 1.63 & n.sh. & n.sh. \\
\hline 6 & 31.670 & 0.985 & 0.568 & 2.446 & 3.11 & 11 & 12 \\
\hline 7 & 25.763 & 3.167 & 1.416 & 3.932 & 12.29 & 11 & 10 \\
\hline 8 & 31.605 & 1.097 & 0.549 & 1.746 & 3.47 & 11 & 8 \\
\hline 9 & 28109 & 186.0 & 107.4 & 462.0 & 0.66 & 11 & 14 \\
\hline 10 & 43187 & 369.0 & 213.0 & 916.6 & 0.85 & 11 & 18 \\
\hline 11 & 42776 & 479.5 & 276.8 & 1191.1 & 1.12 & 11 & 20 \\
\hline 12 & 41114 & 470.5 & 271.6 & 1168.8 & 1.14 & 11 & 22 \\
\hline
\end{tabular}




\begin{tabular}{|c|c|c|c|c|c|c|c|}
\hline 13 & 61035 & 764.0 & 441.1 & 1897.9 & 1.25 & 11 & 23 \\
\hline 14 & 52641 & 111.5 & 64.37 & 277.0 & 0.21 & n.sh. & n.sh. \\
\hline 15 & 50624 & 111.5 & 64.37 & 277.0 & 0.22 & n.sh. & n.sh. \\
\hline 16 & 74931 & 377.0 & 217.7 & 936.5 & 0.50 & n.sh. & n.sh. \\
\hline 17 & 35081 & 479.0 & 276.6 & 1189.9 & 1.36 & n.sh. & n.sh. \\
\hline 18 & 71392 & 540.0 & 311.8 & 1341.4 & 0.80 & n.sh. & n.sh. \\
\hline 19 & 24857 & 103.5 & 59.76 & 257.1 & 0.42 & n.sh. & n.sh. \\
\hline 20 & 26773 & 27.00 & 15.59 & 67.07 & 0.10 & n.sh. & n.sh. \\
\hline 21 & 48486 & 234.7 & 135.5 & 583.0 & 0.48 & n.sh. & n.sh. \\
\hline
\end{tabular}

The variation in the statistic data of area detection (water soluble pectin fractions) were not statistically significant having average Std.dev, average Std. error and average C.I. of means: $3.77 ; 2.13$ and 8.87 , respectively. The average relative standard deviation for area detection of solutions with lower concentration (e.g. water soluble pectin fractions) is $8.93 \%$ (RSD) at $0.7 \mathrm{ml} / \mathrm{min}$ flow rate. The average relative standard deviation for area detection of solutions with higher concentration (e.g. insoluble pectin fractions) is $0.67 \%$ (RSD) at $0.7 \mathrm{ml} / \mathrm{min}$ flow rate. The results show that the proposed method was applied successfully for the assay of pectin fractions in dietary fibers and can be applied for characterizing natural products, pharmaceutical agents as well as commercial dietary fibers.

Each flow rate of HPLC method (e.g. $0.5 \mathrm{ml} / \mathrm{min} ; 0.7 \mathrm{ml} / \mathrm{min}$ ) relates to the generation of a slight different retention time through variety of the concentration. Generation of the slight different retention time forms the basis to the measurement of concentration range. The content of water soluble pectin fraction " $\mathrm{X}$ " in the solution was calculated by the calibration equation: $Y=$ 1009.8X - 14.774. Concentrations of water soluble pectin fraction were summed up in the table 9.

Table 9 Retention times corresponding concentrations of water soluble pectin solutions

\begin{tabular}{lll}
\hline No. & Concentration of the water soluble pectin solution, $\% \mathrm{~g} / \mathrm{ml}$ & Retention time, min \\
\hline 1 & $4.30 \times 10^{-2}$ & 5.601 \\
\hline 2 & $4.40 \times 10^{-2}$ & 5.600 \\
\hline 3 & $5.20 \times 10^{-2}$ & 5.609 \\
\hline 4 & $6.20 \times 10^{-2}$ & 5.599 \\
\hline 5 & $6.60 \times 10^{-2}$ & 5.597 \\
\hline 6 & $6.70 \times 10^{-2}$ & 5.595 \\
\hline 7 & $7.70 \times 10^{-2}$ & 5.596 \\
\hline 8 & $8.90 \times 10^{-2}$ & 5.625 \\
\hline 9 & $12.70 \times 10^{-2}$ & 5.574 \\
\hline 10 & $16.60 \times 10^{-2}$ & 5.589 \\
\hline 11 & $19.50 \times 10^{-2}$ & 5.553 \\
\hline
\end{tabular}

A more appropriate range for the concentration of pectin fractions is a $0.04 \div 0.19 \% \mathrm{~g} / \mathrm{ml}$ (Fig 3C) that the retention time is generated directly in a stable range $5.553 \div 5.625 \mathrm{~min}$ closer to the retention time corresponding to standard pure solution of polygalacturonic acid $(5.600 \mathrm{~min})$. The deviation of value of retention time by diluted of analytes is reduced compared to initial solutions with higher concentration. Pectin solutions were diluted to 1:316.3 ratios in order to obtain detection responses within the range of the standard curve. The chromatogram for this solution is presented in the figure 5B. The relative standard deviation, std.dev, std. error and C.I. of retention time are $0.05 \% ; 0.260$ x $10^{-2} ; 0.082 \times 10^{-2} ; 0.186 \times 10^{-2}$ by using the dilution of initial solutions in 316.3 times, respectively. The relative standard deviation, std.dev, std. error and C.I. of retention time are $0.26 \% ; 1.470 \times 10^{-2} ; 0.463 \times 10^{-2} ; 1.050 \times 10^{-2}$ by using of initial solutions with higher concentration, respectively (Tab 10)

Table 10 The relationship between data of statistical analysis of retention time and dilution in 316.3 times

\begin{tabular}{|c|c|c|c|c|c|c|c|c|c|}
\hline \multicolumn{5}{|c|}{ Initial solution } & \multicolumn{5}{|c|}{ Dilution in 316.3times } \\
\hline $\mathrm{t}, \min$ & SD & SEM & C.I. of mean & RSD, $\%$ & $\mathrm{t}, \mathrm{min}$ & SD & SEM & $\begin{array}{l}\text { C.I. } \\
\text { mean }\end{array}$ & RSD, \% \\
\hline 5.633 & \multirow{10}{*}{$1.470 \times 10^{-2}$} & \multirow{10}{*}{$0.463 \times 10^{-2}$} & \multirow{10}{*}{$1.050 \times 10^{-2}$} & \multirow{10}{*}{0.26} & 5.599 & \multirow{10}{*}{$0.260 \times 10^{-2}$} & \multirow{10}{*}{$0.082 \times 10^{-2}$} & \multirow{10}{*}{$0.186 \times 10^{-2}$} & \multirow{10}{*}{0.05} \\
\hline 5.667 & & & & & 5.604 & & & & \\
\hline 5.616 & & & & & 5.597 & & & & \\
\hline 5.648 & & & & & 5.605 & & & & \\
\hline 5.642 & & & & & 5.599 & & & & \\
\hline 5.630 & & & & & 5.598 & & & & \\
\hline 5.647 & & & & & 5.598 & & & & \\
\hline 5.645 & & & & & 5.600 & & & & \\
\hline 5.652 & & & & & 5.599 & & & & \\
\hline 5.626 & & & & & 5.600 & & & & \\
\hline
\end{tabular}

From a comparison of the all chromatograms, it could be clearly seen that the best separations are those achieved with column $(\mathrm{C} 610 \mathrm{H})$ with using $0.7 \mathrm{ml} / \mathrm{min}$ flow rate.

This paper investigates the application of this HPLC method that can be used to analyze either galacturonic acid, polygalacturonic acid, pectin fractions in dietary fibers or in natural products, pharmaceutical agents. In order to optimize the respective flow rate of elution, the water soluble pectin fraction and insoluble pectin fraction with the different characteristics (molecular weigh $5 \div 70 \mathrm{KDa}$ galacturonic acid content $23.5 \div 74.7 \%$ and $0 \div 37.7 \%$ (DME) methoxyl content of pectin) were used. The formulation of products with water soluble pectin fraction and insoluble pectin fraction is recommended over the use of the calibration equation of polygalacturonic acid for three reasons. Firstly, the typical chromatogram profile of pectin solution by the HPLC method detailed here is corresponded to the chromatogram profile of polygalacturonic acid standard
Secondly, the pectin with the molecular weight $5 \div 70 \mathrm{KDa}$, galacturonic acid content $23.5 \div 74.7 \%$, degree of esterification $0 \div 37.7 \%$ were eluted at the same time as polygalacturonic acid of about $5.600 \mathrm{~min}$ between $5.599 \mathrm{~min}$ and 5.644 min (as shown by figure. $6 \mathrm{~A}, \mathrm{~B}, \mathrm{C}$ ).

Thirdly, previous studies indicated that the pectin may be detected at $210 \mathrm{~nm}$ as the polygalacturonic acid (S.E. Guillotin et.al., 2007) In table 6 and 7 the chromatograms corresponding to most of the samples of water soluble pectin fraction gave two peaks at the retention time of around $5.6 \mathrm{~min}$ and $5.8 \mathrm{~min}$. This explanation may be that these pectin fractions represent a mixture of pectin compounds with various degrees of polymerization, similar chemical structures The method described above can be used to investigate the pectin with heterogeneity. We suggested that the concentration of polydispersity pectin samples having two peaks must be received through summation of all area the related peaks. 

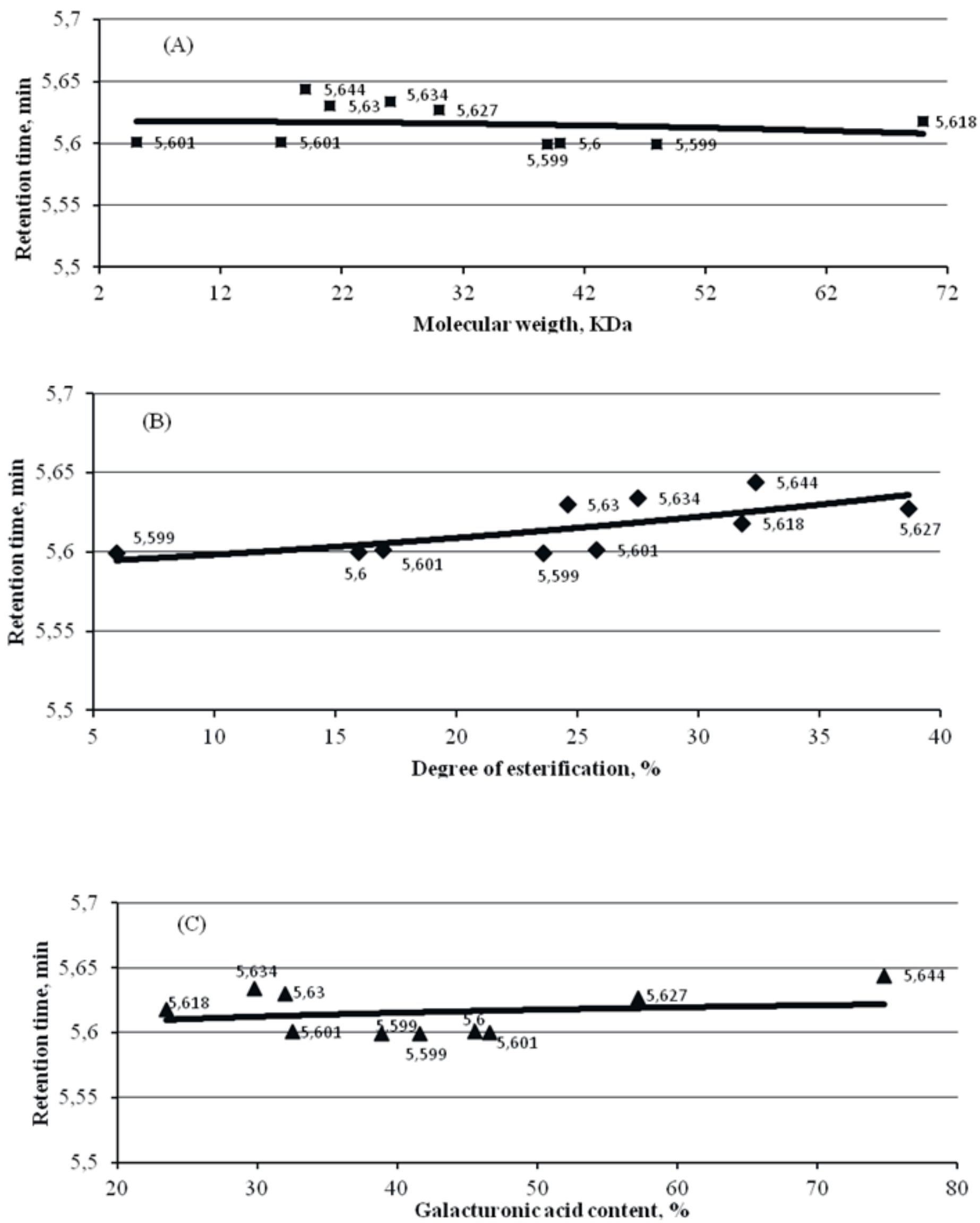

Figure 6 The relationship between the retention time and molecular weight of pectin (A), degree of esterification (DME) of pectin (B) and per cent galacturonic acid in the pectin $(\mathrm{C})$. 


\section{CONCLUSION}

In this study a rapid, accurate, precise, sensitive and selective HPLC method was developed for the determination of galacturonic acid, polygalacturonic acid and pectin compounds. Moreover, this method is simple and inexpensive and it can be employed for the routine quality control of dietary fibers. As shown here, this technique can be used for: "Targeted analysis of pectin compounds in plant tissues". These approaches are useful for characterizing natural products, pharmaceutical agents as well as dietary fibers. This can be used in a wide range of applications, including:

- Quality control

- Compositional analysis

- Product stability

- Competitive analysis

- Nutritional studies.

The retention time $8.557 \mathrm{~min}$ and $5.600 \mathrm{~min}$ can be used to the direct qualification of galacturonic acid and polygalacturonic acid. The retention time around 5.600 min was identified as time for the direct qualification and quantification of pectin fractions in dietary fibers. The line calibration with regression line $Y=1009.8 \mathrm{X}-$ 14.774 was used for the quantification of pectin fractions in dietary fibers. The detection limits $0.04 \% \mathrm{w} / \mathrm{v}$. Good recovery results were obtained for the determination of water soluble and insoluble pectin fraction in 45 varieties of dietary fiber samples in the validation set.

Acknowledgments: The author is very grateful to Roberto Vilaplana for his beneficial suggestions. Financial supports from the "CITROMIL", Murcia, Spain are gratefully acknowledged. The author greatly acknowledges all coworkers of his studies. Finally, the author is also grateful to the University UMH of Elche, Spain.

\section{REFERENCES}

ALFONSO, GARCIA, E. 2010. Estudio Del Comportamiento Reologico De Las Pectinas Con Diferente Grado Galacturonico Obtenida A Partir De Citrus Paradisi (Gray Fruit). San Salvador, El Salvador, Centro America, 137p.

BEDA, MARCEL, YAPO, BERNARD, WATHELET, MICHEL, PAQUOT. 2007. Comparison of alcohol precipitation and membrane filtration effects on sugar beet pulp pectin chemical features and surface properties. Food Hydrocolloids, 21, 245-255.

CATALOG. 2001. Chromatography. Products for analysis and purification. Supelco Sigma-Aldrich Quimica, S.A., 147.

CHEN, Z., G., EN, B., T., \& ZHANG, Z., Q. 2006. Simultaneous determination of eight organic acids in Fructus mume by RP-HPLC. Zhongguo Zhong Yao Za Zhi, 31, 1783-1786.

D., HOURDET, G., Muller. 1991. Solution of Pectin Polysaccharides III: Molecular Size of Heterogeneous Pectin Chains. Calibration and Application of SEC to Pectin Analysis. Carbohydr. Polym, 16, 409-432.

ELIAZ, I. 2011. Binding of galectin-3 by low molecular weight pectin. US Patent, 20110294755.

ELIAZ, I. 2001. The potential role of modified citrus pectin in the prevention of cancer metastasis. Clinical practice of alternative medicine, 2, 1-7.

FEMENIA, A., WALDRON, K., W., ROBERTSON, J., A., \& SELVENDRAN,

R., R. 1999. Compositional and structural modification of the cell wall of cauliflower (Brassica oleracea L. var botrytis) during tissue development and plant maturation. Carbohydrate Polymers, 39 (2), 101-108.

H., G., BARTH. 1980. High-performance gel permeation chromatography of pectins. J. Liq. Chromatogr, 3 (10), 1481-1496.

HUBER, L. 1998. Validation of analytical methods: Review and strategy. LC GC Int, 11 (2), 96-105.

GEOVANA, ROCHA, PLACIDO, MOORE, LUCIANA, RODRIGUES, DO CANTO, \& EDNA, REGINA, AMANTE,. 2005. Cassava and corn starch in maltodextrin production. Quim. Nova, 28 (4), 596-600.

GREGORY, W., WHITE, THOMAS, KATONA, \& JULIUS, P. ZODDA. 1999 The use of high-performance size exclusion chromatography (HPSEC) as a molecular weight screening technique for polygalacturonic acid for use in pharmaceutical applications. Journal of Pharmaceutical and Biomedical Analysis, 20, 905-912.

GUGGENBICHLER, J., P., MEISSNER, P., JURENITSCH, J., \& De BETTIGNIES-DUTZ, A. 1997(a). Blocking the attachment of

germs to human cells. US Patent, 5. 683, 991.

GUGGENBICHLER, J., P., De BETTIGNIES-DUTZ, A., MEISSNER, P., SCHELLMOSER, S., \& JURENITSCH, J. 1997(b). Acidic oligosaccharides from natural sources block adherence of Escherichia coli on uroepithelial cells. Pharm. Pharmacol. Lett., 7, 35-38.

IGNATIEVA, G., N. 2001 Increase in sensitivity of the conductance-measuring method to analyze pectic substances. Storage and processing of farm products, 60-62.

KERRY, HOSMER, CAFFALL, \& DEBRA, MOHNEN. 2009. The structure, function, and biosynthesis of plant cell wall pectic polysaccharides. Carbohydrate Research, 344, 1879-1900.
L., CHENG, \& P., K., KINDEL. 1997. Detection and homogeneity of cell wall pectic polysaccharides of Lemna minor. Carbohydr. Res., 301, 205-212.

M., A., MONSOOR, U., KALAPATHY, A., PROCTOR. 2001. Determination of polygalacturonic acid content in pectin extracts by diffuse reflectance Fourier transform infrared spectroscopy. Food Chemistry, 74 (2), 233-238.

MARSHALL, L., FISHMAN, PHILIP, E., PFEFFER, ROBERT, A., BARFORD, \& LANDIA, W., DONER. 1984. Studies of pectin solution properties by high-performance size exclusion chromatography. J. Agric. Food Chem., 32, 372-378.

NELINA, V., V., DONCHENKO, L., V., KARPOVICH, N., C., \& IGNATYEVA, G., N. 1992. Pectin: Methods in pectin industry. Kiev, 113p. P., D., HOAGLAND, M., L., FISHMAN, GORDANA, KONJA, \& EKKEHARD, CLAUSS. 1993. Size Exclusion Chromatography with Viscosity Detection of Complex Polysaccharides: Component Analysis. J.Agric. Food Chem., 41, 1274-1281.

PIET, J.,H.,DAAS, PETER,W.,ARISZ, HENK,A.,SCHOLS, GERHARD, A., DE RUITER, ALPHONS, G.,J.,VORAGEN. 1998. Analysis of partially methylesterifified galacturonic acid oligomers by high-performance anion-exchange chromatography and matrix-assisted laser desorption/ionization time-of-flight mass spectrometry. Analytical Biochemistry, 257 (2), 195-202.

RAVIN, GNANASAMBANDAM, PROCTOR, A. 1999. Preparation of soy hull pectin. Food Chemistry, 65 (4), 461-467.

RIDLEY, B., L., O'NEILL, M., A., MOHNEN, D. 2001. Pectins: structure, biosynthesis, and oligogalacturonide-related signaling.

Phytochemistry, 57 (6), 929-967.

SANG-HO, YOO, MARSHALL, L., FISHMAN, ARLAND, T., HOTCHKISS, Jr., HYEON, GYU, LEE. 2006. Viscometric behavior of high-methoxy and lowmethoxy pectin solutions. Food Hydrocolloids, 20, 62-67.

SARA, C., CUNHA, JOSÉ, O., FERNANDES, ISABEL, M.,P.,L.,V.,O., FERREIRA. 2002._HPLC/UV determination of organic acids in fruit juices and nectars. Eur Food Res. Technol., 214 (1), 67-71.

SCHOLS, H., A., REITSMA, J., C., E., VORAGEN, A., G., J., \& PILNIK, W. 1989. High performance ion exchange chromatography of pectins. Food Hydrocolloids, 3 (2), 115-121.

SELVENDRAN, R, R., MARCH, J., F, \& RING, S., G. 1979. Determination of aldoses and uronic acid contents of vegetable fiber. Anal. Biochem, 96, 282-292. S.,E.,Guillotin, A.,Van,Loey, P.,Boulenguer, H.,A.,Schols, \& A.,G.,J.,Voragen 2007.

Rapid HPLC method to screen pectins for heterogeneity in methyl-esterification a nd amidation. Food Hydrocolloids, 21 (1), 85-91.

S., VIDAL, P., WILLIAMS, M., A., O'NEILL, P., PELLERIN. Polysaccharides from grape berry cell walls. Part I: tissue distribution and structural characterization of the pectic polysaccharides. Carbohydrate polymers, 45, 315323

THOMAS, STOLL, ANDREAS, SCHIEBER, REINHOLD, CARLE, 2003. Quantitative determination of saturated oligogalacturonic acids in enzymatic digests of polygalacturonic acid, pectin and carrot pomace by on-line LC-ESIMS. Anal. Bional. Chem., 377(4), 655-659. 